\title{
ENTRE FAMÍLIAS - ALIANÇAS MATRIMONIAIS VINCULADAS AS RELAÇÕES DE PODER: PADRES E FILHOS, MINAS GERAIS (SÉCULO XVIII E XIX) ${ }^{1}$
}

\author{
AMONGST FAMILIES - MARRIAGE ALLIANCES LINKED TO POWER \\ RELATIONS: PRIESTS AND CHILDREN, MINAS GERAIS (18TH AND 19TH \\ CENTURIES)
}

\section{CONTRATOS MATRIMONIAIS AGENCIADOS POR PADRES}

\section{MARRIAGE CONTRACTS NEGOTIATED BY PRIESTS}

\author{
JULIO, Kelly Lislie ${ }^{2}$ \\ NOLASCO, Edriana Aparecida ${ }^{3}$
}

\begin{abstract}
Resumo
Este artigo pretende trazer algumas considerações sobre as ações familiares ligadas aos contratos de casamentos instituídos em Minas Gerais desde os fins do século XVIII até as primeiras décadas do século XIX. A proposta é demostrar como o casamento era percebido sobretudo como um negócio de família, voltado para o estabelecimento ou reforço de relações de poder, sejam elas econômicas, sociais ou políticas. Também almeja debater a respeito do casamento enquanto um valor que deveria ser difundido e internalizado com vistas ao ordenamento da população. Tais aspectos serão analisados a partir das famílias em que seus chefes eram padres e, por isso, impedidos de sacramentar suas uniões. Como será demonstrado, a partir de dados presentes nos inventários desses indivíduos e de seus familiares, essas famílias agiam de modo similar às demais e, por isso, utilizavam das mesmas estratégias, tais como: a celebração de matrimônios entre "iguais" e, também, davam dotes para suas filhas. Dessas ações, sociedades e parcerias eram estabelecidas concorrendo para a ampliação ou manutenção de determinados domínios que acabaram interferindo de maneira fundamental na conformação e desenvolvimento da sociedade mineira.
\end{abstract}

Palavras-chave: casamento; prestígio; ordenamento; grupo familiar

\footnotetext{
${ }^{1}$ Parte desta pesquisa conta com o apoio da Fundação de Amparo à Pesquisa e Desenvolvimento Científico do Maranhão - FAPEMA.

${ }^{2}$ Doutora em Educação pela Faculdade de Educação da Universidade Federal de Minas Gerais. Professora Pesquisadora do Curso de Pedagogia da Universidade Federal do Maranhão/ Campus Imperatriz - MA (UFMA). Grupo de Pesquisa: GCEAP/GEPHE kellylislie@gmail.com

${ }^{3}$ Doutoranda em História pela Faculdade de Filosofia e Ciências Humanas da Universidade Federal de Minas Gerais (UFMG).
} 


\begin{abstract}
This article intends to present some considerations about family practices related to marriage contracts instituted in Minas Gerais from the end of the 18th century until the first decades of the 19th century. Our proposal is to demonstrate how marriage was mainly perceived as a family business, aimed at establishing or strengthening power relations, whether economic, social or political ones. It also aims to discuss marriage as a value that should be disseminated and internalized, in order to plan the population. These aspects will be analyzed within families whose heads were priests. Hence, these priests were prevented from consecrating their unions. As it will be shown, based on data present in the inventories of these individuals and their relatives, these families acted in a similar way to other families and, therefore, they used the same strategies, such as: the celebration of marriages between "equals" and, also, the offering of endowments to their daughters. With such practices, associations and partnerships were established for the expansion or maintenance of certain domains that ended up interfering, in a fundamental way, in the organization and development of Minas Gerais society.
\end{abstract}

Keywords: marriage; prestige; planning; family group

\title{
Introdução
}

Os estudos relacionados à história da família têm contribuído para sua definição e redefinição conceitual e favoreceram, ao longo do tempo, o entendimento de seu significado plural. Não se aplica mais a concepção de um único modelo familiar dominante, mas há a concordância e aceitação da existência de múltiplos tipos de famílias que, conforme Silva e Silva (2010) devem ser consideradas em decorrências das condições históricas de cada sociedade.

No caso do Brasil dos séculos XVIII e XIX, os estudos historiográficos, influenciados pela Antropologia e Sociologia, demonstraram que a noção de família não deve ser limitada aos grupos familiares que se uniram mediante os laços do matrimônio e que compartilhavam o mesmo domicílio ${ }^{4}$. O termo família deve ser utilizado também para definir as relações que se estabeleceram à margem das normatizações veiculadas pela Igreja e o Estado ${ }^{5}$.

\footnotetext{
4 "O discurso científico sobre a família nasceu no século XIX, quando antropólogos e sociólogos observaram a importância do parentesco e do casamento nas sociedades ditas "primitivas"” (CAMPOS, 2003, p. 15). Na década de 80, Marisa Corrêa foi precursora nesse debate considerando que outras formas de constituições familiares coexistiram com o modelo patriarcal (CORRÊA, 1982).

${ }^{5}$ Em seus estudos sobre a família em Minas Gerais, Figueiredo (1997) afirmou que havia uma parceria entre a Igreja e o Estado no sentido de disseminar a preservação da família legítima.
} 
Em Minas Gerais, vários estudos já evidenciaram a multiplicidade de arranjos familiares que caracterizavam aquele espaço ${ }^{6}$. Conforme tais estudos, paralelamente às uniões sancionadas pelos poderes eclesiásticos e civis, formavam a base daquela sociedade os arranjos familiares marcados pelo concubinato $^{7}$ - coabitando ou não -; parentes que partilhavam o mesmo domicílio; mulheres viúvas com ou sem a sua prole; mães solteiras; pais solteiros; dentre outros.

Apesar dessa diversidade, o casamento sacramentado, enquanto um valor, foi difundido e internalizado pela sociedade mineira (ANTUNES, 2005, p.48). Isso porque, nas palavras do autor, havia, de um modo geral, um reconhecimento das pessoas casadas que eram vistas como "pessoas de respeito, ciosas de ordem, da moral e dos bons costumes".

No presente artigo, a intenção é demonstrar tal aspecto. Para isso, a análise buscará evidenciar que era uma prática comum por parte de algumas famílias constituídas fora da legitimidade dada pela Igreja e o Estado, a propagação de tal concepção. Nesse sentido, buscavam garantir que seus filhos tivessem um casamento sacramentado como forma de dignificá-los (ALGRANTI, 1997). Para além desse aspecto, a proposta é demonstrar como os casamentos foram utilizados como um "negócio de família".

$\mathrm{Na}$ tentativa de alcançar tais objetivos, foram eleitas, no presente estudo, as famílias formadas pelos padres. Os padres, embora "impedidos" ${ }^{8 "}$ pela condição sacerdotal de arranjarem mulheres e terem filhos, os tiveram e viveram "maritalmente", constituindo um tipo de arranjo familiar ${ }^{9}$. Conforme destacou Mendonça (2007), alguns padres tiveram relacionamentos bastante estáveis. E, de modo semelhante às outras pessoas que não eram impedidas de se casarem, buscaram desenvolver no seio de suas famílias diferentes projetos visando interesses econômicos, políticos ou sociais. Nesse conjunto, agiram de modo que suas

\footnotetext{
${ }^{6}$ Autores como SAMARA (1989); (FARIA, 1998 e 2011), dentre outros, demonstraram a diversidade de arranjos familiares existentes na sociedade brasileira. Para Minas Gerais, essa realidade foi evidenciada por pesquisadores: (FIGUEIREDO, 1997); (BRUGGER, 2007); (NOLASCO, 2014); (JULIO, 2017); etc.

${ }^{7} \mathrm{O}$ concubinato poderia ser classificado em diversas modalidades: o simples, proveniente das relações entre solteiros, que podia ser usual, esporádica ou duradoura; o adulterino, resultado da relação em que um dos envolvidos era casado; o incestuoso, que comportava a relação entre parentes; o clerical, que consistia no relacionamento em que um ou ambos pertencia(m) ao mundo religioso; o misto, que significava a junção de concubinos que estivessem em adultério e incesto ao mesmo tempo; o duplo ou poligâmico, que era uma relação que admitia vários parceiros; e o com promessa de casamento que não fora cumprida por um dos concubinos, (NETTO, 2008).

${ }^{8}$ As relações amorosas vivenciadas pelos padres com as mulheres recaíam em duplo crime, pois violavam dois sacramentos: o do Matrimônio e da Ordem, sendo este último associado ao celibato (LOTT, 2008).

${ }^{9}$ Para saber mais sobre as relações conjugais vivenciadas pelos padres, ver: MENDONÇA (2007); NOLASCO (2014).
} 
famílias construíssem e reconhecessem valores similares aos demais grupos familiares, dentre eles, aqueles formados pelo sacramento do matrimônio.

\section{Os contratos matrimoniais como um "negócio de família"}

Conforme destacou Fonseca (2014b, p. 02), entre o século XVIII e as primeiras décadas do século XIX, existia uma concepção de educação "que a entendia como um conjunto de ações voltadas para a formação do súdito cristão". Nesse entendimento, a educação, empreendida pelas mais diversas instituições e em diferentes espaços, seria uma oportunidade de difundir valores, comportamentos e normas.

A família, compreendida como uma dessas instituições educativas, deveria dar a sua parcela de contribuição e ajudar no processo de modo que as pessoas pudessem ser ordenadas para viver em sociedade. Assim, deveria trabalhar para que seus membros manifestassem determinados valores, comportamentos e visões de mundo conforme os estabelecidos pela Igreja e o Estado.

Esse é o caso das uniões sacramentadas que, no período, era um dos grandes propósitos das autoridades civis e religiosas. Como destacou Algranti (1997, p. 87), o casamento sacramentado "conferia status e segurança aos colonos, tornando-o desejável tanto pelos homens como as mulheres". A mesma autora destacou ainda que, apesar de ser uma instituição primordialmente da elite, a condição de casado era almejada por indivíduos pertencentes a grupos sociais variados.

O casamento representava uma materialização do respeito e obediência às leis reais e da religião. Sendo assim, cabia às famílias mineiras contribuir para a propagação da condição de casado, ajudando no processo de ordenamento e busca de uma civilidade na região. Por meio do casamento era possível manter laços de afetividade, inserir-se na sociedade, preservar a honra e o "bom comportamento" das pessoas.

A partir da documentação analisada foi possível observar que as uniões sacramentadas foram buscadas por diferentes famílias, inclusive por aquelas em que os chefes eram padres ${ }^{10}$. Em outros termos, os padres, do mesmo modo que outros pais de família, criaram algumas

\footnotetext{
${ }^{10}$ Não é intenção aqui afirmar que o casamento foi uma prioridade para todos os grupos sociais. Como destacou Praxedes (2008), o casamento assumia, muitas vezes, uma posição dúbia, pois era considerado um estado ideal, mas, ao mesmo tempo, não ocupava uma posição de primeira urgência e necessidade. Para além dessa questão, é importante ressaltar que muitos acordos e alianças de natureza variadas, como comerciais, sociais e políticas, poderiam se dar por outras vias. A proposta é pensar o casamento como um valor desejado e valorizado pelos diferentes indivíduos e que acabou sendo praticado pelo diferentes grupos e arranjos familiares, visando interesses diversos, dentre eles: a preservação de bons costumes; a manutenção da ordem e também dos bens; a consolidação de alianças, etc.
} 
estratégias para casar seus filhos, evidenciando aí um processo em curso que tinha como propósito a proliferação de matrimônios legitimados pela Igreja e o Estado.

O Padre João Pedro dos Santos, por exemplo, declarou em petição presente no inventário do Padre André Vaz de Siqueira que havia contratado o casamento de um dos seus filhos, Agostinho Nolasco dos Santos ${ }^{11}$. Conforme o Padre João, Ana Rita estava morando em sua casa e se achava com dezessete anos de idade. Já Agostinho, de acordo com o padre, era uma pessoa de "bons costumes". O casamento, segundo o citado padre, foi feito com o seu consentimento e, apesar de não ter procurado licença do Juiz de Órfãos, tal ação não havia sido feita em desobediência à lei, mas sim porque ignorava essa necessidade. Como se percebe, ainda que inobservadas as questões ligadas ao juizado de órfãos, houve, por parte do padre, uma preocupação em buscar fazer um contrato e celebrar um casamento sacramentado. Para isto, esteve atento às circunstâncias que favorecia essa união, beneficiando o destino de sua acolhida e de seu filho e, ao mesmo tempo, garantindo "a boa reputação" de todos.

Mas, além do estabelecimento de contratos, houve ainda algumas práticas relacionadas com a doação de bens, especialmente para as mulheres, que se mostraram extremamente importantes para a celebração de casamentos. Dessas práticas, destaca-se o dote.

Como será destacado mais adiante, os dotes foram importantes sobretudo quando ligados às questões materiais e econômicas do futuro casal. Todavia, não se pode deixar de destacar nessa prática também uma afirmação do casamento sacramentado. No período, era o casamento que tornava possível e legítimo a doação de bens para alguma filha com o consentimento dos demais descendentes. Isso acabava ratificando-o como uma prática importante, pois era a materialização do respeito às leis civis.

O Padre Joaquim de Carvalho, natural de Barbacena, por exemplo, declarou em testamento que havia dotado sua filha Maria e também a neta quando se casaram ${ }^{12}$. Segundo ele, para terem direito à partilha que seria feita com o inventário e de modo que não ficassem prejudicados os demais herdeiros, elas deveriam declarar esses dotes. Nesse sentido, o auxílio dado por meio do dote respeitou o que era estabelecido pela legislação e, ao mesmo tempo, contribuiu para dar "estado de casadas" para sua filha e neta.

Mas, além do dote, uma outra prática que acabou contribuindo para que as pessoas no período pudessem "tomar estado de casadas" foi o legado testamental. As doações em

\footnotetext{
${ }^{11}$ AHETII/IPHAN/SJDR. Inventário do Padre André Vaz de Siqueira... 1827, fl. 66.

${ }^{12}$ AHMPAS/BARBACENA. Testamento do padre José Joaquim de Carvalho... 1844, fl. 72.
} 
testamento eram bastante comuns. Entretanto, o que diferenciava essa prática quando ligada ao casamento era o fato de que, muitas vezes, ela estava acompanhada da declaração de que caso o legatário não se casasse, tal doação ficava sem efeito (JULIO, 2017).

O Padre Francisco José da Fonseca, em testamento produzido em 1748 na Comarca de Vila Rica, declarou que tinha umas casas em Pernambuco ${ }^{13}$. Conforme sua determinação, elas deveriam ser vendidas e da negociação deveria ser retirado quatrocentos mil réis que deixava à mulata Jacinta "para seu dote de casamento". Além disso, ressaltou que caso a mesma não tomasse estado de casada, o valor deveria ser convertido em missas por sua alma. Como se vê, a "proteção" e o investimento para a celebração do casamento poderia se estender para outras pessoas. Além disso, como apontado, a doação estava intimamente ligada à efetivação do matrimônio sacramentado e à propagação dos preceitos religiosos ligados à formação da "família cristã"14.

Mas, para além da função de ordenar, o casamento e todas as estratégias fomentadas para a sua realização tiveram papel fundamental em outros aspectos da sociedade, como o político, o econômico e o social ${ }^{15}$. Na verdade, como apontaram alguns estudos, as ações desenvolvidas a partir das alianças matrimoniais acabaram influenciando decisivamente o processo de constituição da sociedade, seja no período colonial como também durante o Império do Brasil ${ }^{16}$.

No caso de Minas Gerais, desde o processo de constituição das vilas mineiras, foram as estratégias familiares que garantiram o desenvolvimento da região. Em outros termos, foi a presença do trabalho familiar que tornou possível a efetiva exploração aurífera e o surgimento e desenvolvimento paralelo de outras atividades econômicas como a agricultura, a pecuária e

\footnotetext{
${ }^{13}$ ACSM/IPHAN. Inventário do Padre Francisco José da Fonseca... 1748, n.p.

${ }^{14}$ Essa afirmação de maneira nenhuma implica num entendimento de que essas práticas foram sempre realizadas intencionalmente, com vistas a ensinar tais prescrições. Todavia, ao serem praticadas, acabavam contribuindo para a difusão das uniões sacramentadas, o que era um dos grandes propósitos da Igreja e Estado no período, com vistas ao ordenamento da população.

15 É importante destacar que a influência exercida pelas famílias não foi uma exclusividade das uniões sacramentadas. Como ressaltaram alguns estudiosos, os diferentes tipos de organização familiar tiveram importância fundamental no processo de desenvolvimento da sociedade. Faria (2011, p. 243), por exemplo, defendeu a ideia de que as famílias - constituídas de diferentes maneiras - exerceram "importância fundamental na montagem e funcionamento das atividades econômicas e nas relações sociais e políticas". Entretanto, em decorrência dos interesses do presente artigo, a análise se restringirá aos matrimônios celebrados pela Igreja e Estado.
}

${ }^{16}$ Alguns estudos se detiveram sobre a importância da família nos rumos da sociedade. Ver: ANDRADE (2008); BRÜGGER (2007); NOLASCO (2014); SAMARA (1989); FREYRE (2006); CAMPOS (2003); LEWCOWICZ (1993); LOTT (2008); entre outros. 
o comércio. Nesse contexto, o casamento ocorrido dentro e fora do grupo familiar se mostrou fundamental, pois era da parceria entre pais, filhos e genros que tornava possível o sucesso e a ampliação dos negócios, sejam aqueles ligados à produção quanto à comercialização dos diferentes produtos (ANDRADE, 2008).

O casamento também foi essencial na região no que diz respeito à ampliação dos bens e à manutenção das posses no interior das famílias. Por causa disso, a obediência dos filhos se mostrou basilar quando a questão estava relacionada às alianças matrimoniais a serem estabelecidas. Afinal, como bem destacou Brügger (2007), eram os interesses das famílias que norteavam as intenções do grupo e não os individuais e, sendo assim, o casamento era visto como um projeto familiar, pois era uma forma de agregar e/ou manter valores econômicos e materiais.

Observando a documentação pertencente às famílias dos padres, foi possível perceber que havia um esforço particular em realizar "bons casamentos" com vistas a agregar determinados valores, sobretudo econômicos. Este é o caso, por exemplo, do já mencionado sacerdote João Pedro dos Santos que, por volta de 1838 no Arraial de Conceição da Barra, Comarca do Rio das Mortes, contratou um de seus filhos para se casar com a herdeira do Padre André $\mathrm{Vaz}^{17}$. Segundo alegações do citado padre, seu filho "tinha todas as circunstâncias e iguais possibilidades para se poder casar com a dita". Essas "iguais possibilidades" a que se referia o Padre João Pedro certamente estavam relacionadas, dentre outros aspectos, à questão das posses. Isso porque a noiva era herdeira do Padre André Vaz que, por sua vez, tinha propriedades no Arraial de Conceição da Barra, onde o referido padre também mantinha vários bens.

O estabelecimento de alianças matrimoniais se fazia importante ainda quando consideradas as questões ligadas ao gerenciamento dos negócios. O grande fazendeiro e Padre Francisco Ferreira da Silva, por exemplo, teve na pessoa do genro uma possibilidade de ampliar e dividir parte da administração de seus bens. Morador no Arraial de Conceição da Barra na Comarca do Rio das Mortes, ele era sócio de seu genro Eugênio, com quem lavrou escritura de sociedade em $1840^{18}$. Além desse aspecto, eram as filhas e o genro Eugênio os responsáveis por cuidar de seus escravos e fazenda.

\footnotetext{
${ }^{17}$ AHETII/IPHAN/SJDR. Inventário do Padre André Vaz de Siqueira... 1827, fl. 66.

${ }^{18}$ AHETII/IPHAN/SJDR. Inventário do Padre Francisco Ferreira da Silva... 1843.
} 
As atividades desenvolvidas na Fazenda do Tanque, propriedade do Padre Francisco, se relacionavam ao cultivo de cana e a consequente produção de açúcar e aguardente, diversas plantações de milho, feijão e arroz, além da criação de gado. A produção se destinava ao consumo familiar e ao comércio, daí a necessidade de mão de obra escrava, que somava o total de 44 cativos, e o engajamento e a colaboração mútua de todos os membros da família, inclusive do genro.

Mas, para que pudessem de modo efetivo corresponder aos interesses da família, era necessário que os casamentos ocorressem "entre iguais". Sendo assim, do mesmo modo que as demais famílias, entre aquelas em que o chefe era um padre, houve uma tentativa de buscar genros e noras que tivessem uma condição econômica ou social semelhante à de seu grupo familiar. Quer dizer, pais de famílias, sacramentadas ou não, desejavam a ascensão econômica familiar e, para isso, tratavam de fomentar e contratar casamentos de seus filhos com pessoas de sua "igualha".

A busca pela igualdade, seja ela jurídica (de pessoa) ou econômica, era uma premissa nas políticas matrimoniais. Ser igual implicava, dentre outros aspectos, ter o que trocar. Nisto, o matrimônio funcionava como elemento formador de alianças entre famílias que tinham interesses recíprocos. Estes poderiam ser: prestígio social, riqueza, inserção nas redes de poder, entre outras possibilidades (BRUGGER, 2007). Celebrar casamentos sem considerar tais elementos poderia ocasionar o fracionamento dos bens materiais, bem como anular as possibilidades de projeção econômica, política e social.

É também referente à projeção que a questão da identidade familiar e o prestígio social funcionavam como elementos motivadores da implementação dessa política conjugal baseada em contratos. Como já dito, o casamento representava um negócio entre famílias e, por isso, casar-se dentro da mesma condição social era uma prática defendida por muitos, pois o que estava em jogo era a manutenção do patrimônio ou, ainda, a ampliação e a garantia de prestígio familiar (LOTT, 2008). Por isso, pensando na questão da igualdade entre os pares, as famílias lançavam mão de estratégias, tais como as uniões endógenas ou exógenas como modo de garantir ou ampliar o patrimônio ${ }^{19}$.

O Padre Antônio Francisco Junqueira, herdeiro de uma família abastada na Freguesia de Carrancas, no sul de Minas, possuía sete filhos. Desse total, metade deles se casaram com

\footnotetext{
${ }^{19}$ Uniões endógenas seriam aquelas realizadas entre os membros de uma mesma família. Já os contratos matrimoniais exógenos eram aqueles celebrados com pessoas que não pertenciam ao grupo familiar, mas que tinham condições econômicas, sociais ou políticas similares.
} 
primos. Conforme Andrade (2008), seria a busca pela estabilidade econômica no interior da família que teria estimulado a realização de diversos casamentos endogâmicos. Em outros termos, a fim de garantir a solidez e a conservação dos bens no interior da família, nada mais seguro do que o casamento entre os membros do mesmo grupo familiar, pois assim evitaria que outras pessoas tivessem direito nas posses posteriormente.

Foi a segurança dos bens que também motivou o casamento de Maria Madalena, filha do já citado Padre Francisco Ferreira, com seu sobrinho, João Nepomuceno ${ }^{20}$. A celebração desse matrimônio garantia que a riqueza significativa do referido padre, composta por fazendas e muitas terras, não fosse dividida, causando assim a deterioração das posses da família.

Aureliano Correa Pamplona era filho do Padre José Maria Correia Pamplona. Do mesmo modo que as demais famílias mencionadas acima, ele era oriundo de um grupo familiar afortunado que residia na Comarca do Rio das Mortes ${ }^{21}$. Aureliano se casou com sua própria sobrinha Domiciana Ludmila Pamplona, filha de sua irmã Maria Ludmila. Ainda na mesma família, Maria Constância, neta do referido Padre José Maria, se uniu com seu primo Pedro Teixeira de Carvalho.

Mas, além da prática do casamento endógeno, a documentação revelou que a família Pamplona também buscou estabelecer laços com outras pessoas distintas da localidade onde morava. Conforme destacou Andrade (2008), os casamentos arranjados fora do círculo familiar eram bem pensados e planejados para que pudessem servir como meio de ampliação das fortunas. O herdeiro Herculano, filho do mesmo Padre José Maria, declarou em petição presente no inventário que havia estabelecido contrato com Joaquim Henrique Pereira para casar sua irmã e tutelada Guilhermina Amélia Pamplona. Conforme declaração do referido tutor, o noivo era "seu igual tanto em qualidade como em fortuna ${ }^{22}$ " e, por isso, dava seu consentimento para a celebração do casamento. Em outros termos, foi o fato de o pretendente ser igual à noiva em "qualidade" e "fortuna" que o levou a autorizar aquela união, vislumbrando uma oportunidade de aumentar as posses e a importância econômica da família.

\footnotetext{
${ }^{20}$ AHETII/IPHAN/SJDR. Inventário do Padre Francisco Ferreira da Silva... 1843.

${ }^{21}$ AHETII/IPHAN/SJDR. Inventário do Padre José Maria Correa Pamplona... 1854.

${ }^{22}$ AHETII/IPHAN/SJDR. Inventário de Senhorinha Cândida Rodrigues... 1855, fl. 59.
} 
Em meados do século XIX, Lucrécia Rodrigues Milagres, filha e herdeira do Padre Felisberto Rodrigues Milagres, fez uma petição solicitando uma autorização para se casar ${ }^{23}$. Segundo a sua declaração, ela se achava "justa e contratada para se receber canonicamente em matrimônio com José Dias Neto seu igual em condições". Assim como os demais casos destacados, Lucrécia havia incorporado a concepção de que um casamento se fazia necessário e importante na época, não apenas para si mas para toda família. E, mais do que isso, de que ele deveria ser feito entre "iguais". Por isto, era fundamental ressaltar tal aspecto como forma de alcançar a aprovação do juiz de órfãos.

Para além da questão econômica, os contratos matrimoniais feitos afora do grupo familiar poderiam representar também uma oportunidade para ampliar o prestígio social dos noivos e de suas famílias. Acredita-se que o Padre João da Costa Guimarães pode ter contratado um casamento para sua filha Ana Custódia da Costa ${ }^{24}$. Esta se casou com o Sargento Mor Joaquim Bonifácio Fernandes Brasiel, filho do Tenente Lourenço José Fernandes Brasiel ${ }^{25}$. Além das patentes militares que os dois possuíam ${ }^{26}$, consta que eles eram músicos, ocupação que, no período, conferia certo prestígio (NOLASCO, 2014).

A família Brasiel tinha a música como meio de sobrevivência, pois dentre os bens de Lourenço José Fernandes Brasiel, pai do genro do padre, consta vários instrumentos e partituras. Conforme destacou Eduardo Coelho (2011) a composição e a regência concedia certa distinção na sociedade daquele período. Essa distinção provavelmente foi reforçada se for levado em conta o fato de que, durante longos anos, essa família esteve ajustada com a Ordem Terceira de São Francisco em São João del-Rei para a execução do ofício musical27.

\footnotetext{
${ }^{23}$ AHETII/IPHAN/SJDR. Inventário do Padre Felisberto Rodrigues Milagres... 1854, fl. 23.

${ }^{24}$ AHETII/IPHAN/SJDR. Inventário do Padre João da Costa Guimarães... 1836.

${ }^{25}$ A preocupação com essa filha e a família de um modo geral seria evidenciada em outras ocasiões. Consta uma escritura de perfilhação datada de 1819 em que o referido padre reconheceu como filhos Ana Custódia e João Pedro Celestino da Costa. Nela, o padre João da Costa Guimarães declarou que os reconhecia como "seus filhos naturais", pois desejava deixá-los "por socorridos", depois de sua morte. Quer dizer, em condições de serem herdeiros de seus bens quando falecesse. AHETII/IPHAN/SJDR. Escritura de Perfilhação do Padre João da Costa Guimarães... 1819, fl. 47v. No período da perfilhação Ana Custódia já se encontrava casada. Conforme o registro do casamento, este teria ocorrido em 1811, quando ela teria 17 anos de idade. AEMNSP/SJDR. Registro de Casamento de Ana Custódia... 1811, 641.

${ }^{26}$ Sobre a organização militar de Portugal e seus domínios no período estudado e os privilégios concedidos a cada uma delas, ver Cotta (2014).

${ }^{27}$ A partir das informações presentes no inventário de Lourenço José Fernandes Brasiel, pai do genro do padre o Sargento Mor Joaquim Bonifácio Fernandes Brasiel - é possível conjecturar a existência de um processo educativo nessa família que permitiu que, assim como o pai, os filhos e genros pudessem viver da arte da música. Isso porque, conforme petição presente no citado inventário, consta que tanto o pai, quando o filho -
} 
Ainda em relação a essa família é importante ressaltar que, além da música como elemento importante para demarcar a distinção, consta que dois irmãos do genro do padre também tinham seguido a carreira sacerdotal ${ }^{28}$. Conforme Ida Lewcowicz (1987, p. 56), o fato de ser padre conferia status familiar. De acordo com a autora, era uma prática comum entre as famílias "a reserva de um filho para padre ou uma filha para freira, [como] garantia de prestígio social e possibilidade de ascensão”. Assim, a união dessas famílias como forma de ampliar o poder e o prestígio social poderia ser pensada levando em consideração também tal aspecto.

A partir dos casos apresentados até aqui, é possível perceber como os casamentos foram importantes para garantir a expansão do poder das famílias, seja econômico, social ou político. Os contratos matrimoniais foram almejados e praticados por diferentes tipos de arranjos familiares, inclusive por aqueles que viveram à margem da Igreja e do Estado. Como foi possível perceber, o casamento sacramentado era um estado ideal naquela sociedade do final do século XVIII e início do século XIX.

É certo que, como já dito, o estado de casado não representou uma necessidade para muitas pessoas que construíram suas famílias baseadas em outros acordos. Todavia, a partir de um "bom casamento", foi possível estabelecer relações de poder, consolidar essas relações e, também, em alguns casos, garantir a sobrevivência, inclusive econômica, dos herdeiros.

A fim de evidenciar de modo mais circunscrito alguns desses aspectos apresentados até aqui, foi eleita a família do Padre Domingos Vaz de Carvalho. Como será possível observar, as relações construídas entre esse padre e seu genro garantiu a ampliação e fortalecimento de suas condições econômicas. Para além desse aspecto, o casamento entre a filha parda e um português possibilitou determinada ascensão social, pois, no período, a ascendência portuguesa era elemento distintivo.

\section{Padre Domingos e o casamento de suas filhas - um estudo de caso}

Por volta de 1788, o Padre Domingos Vaz de Carvalho decidiu mandar redigir suas últimas vontades em testamento. Conforme sua declaração, ele era morador em Vila Rica e natural de Portugal. Além disso, mencionou que era filho legítimo de Pedro Vaz e de sua

\footnotetext{
Sargento Mor Joaquim - e o genro - João Leocádio do Nascimento - eram músicos. AHETII/IPHAN/SJDR. Inventário de Lourenço José Fernandes Brasiel... 1833.

${ }^{28}$ Os filhos do músico Lourenço eram os padres Francisco de Assis Brasiel e outro falecido por nome Antônio da Trindade. AHETII/IPHAN/SJDR. Inventário de Lourenço José Fernandes Brasiel... 1833.
} 
mulher Maria Gonçalves, já falecidos no período, que era presbítero do Hábito de São Pedro e, finalmente, que nunca havia se casado ${ }^{29}$. Entretanto, antes de ordenar havia tido oito filhos, pertencentes a quatro mulheres diferentes, todas "de cor", conforme pode-se observar abaixo:

\section{DIAGRAMA 01 -Família do padre Domingos Vaz}

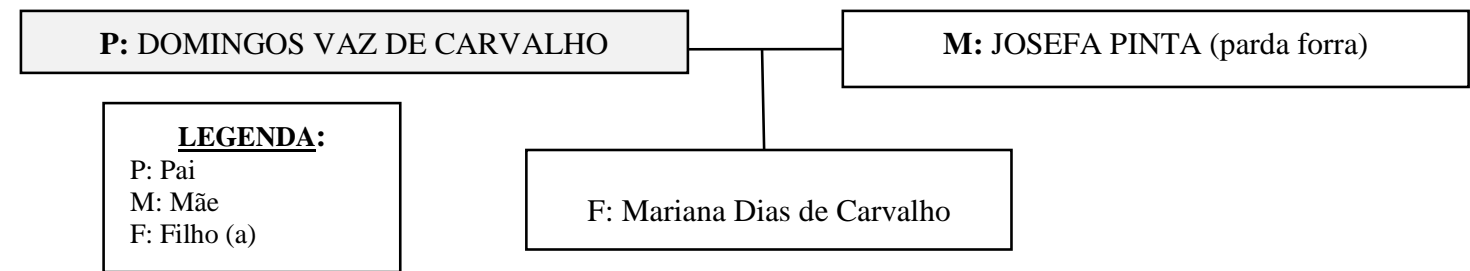

DIAGRAMA 02 - Família do padre Domingos Vaz

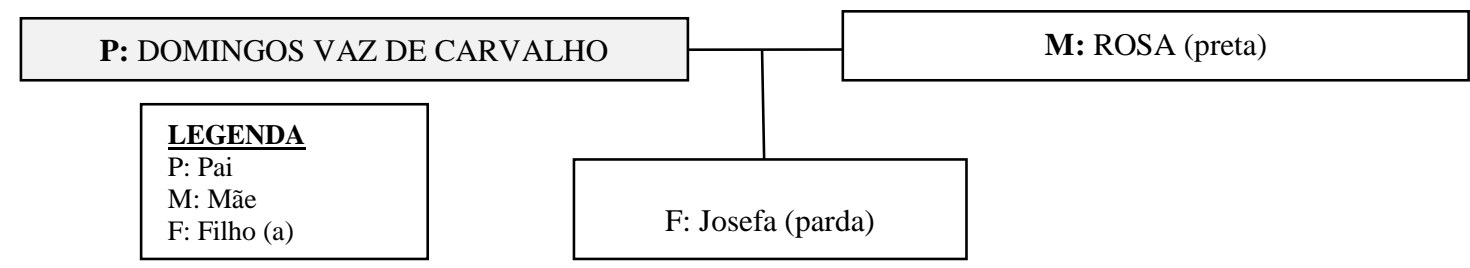

DIAGRAMA 03 - Família do padre Domingos Vaz

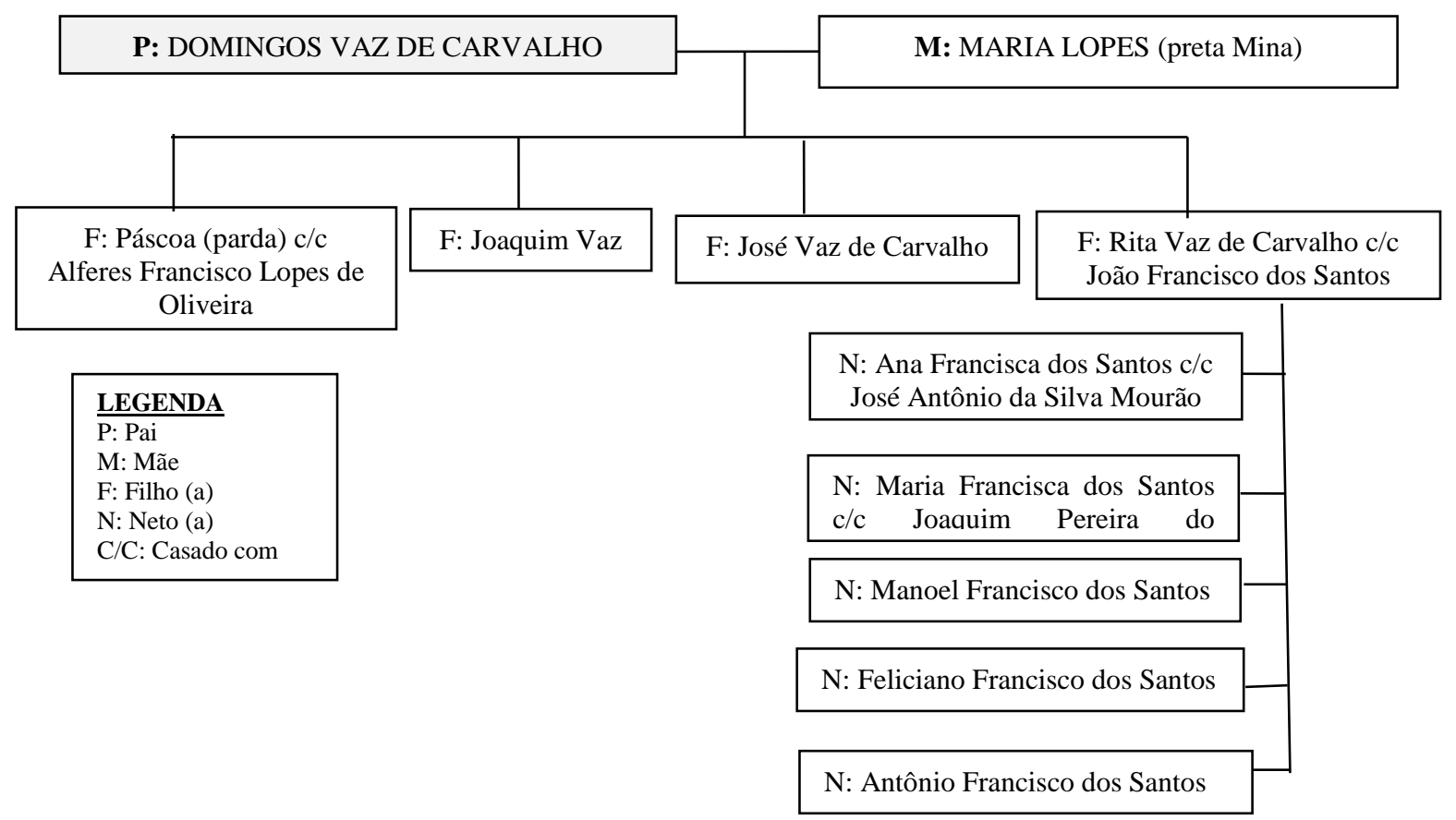

DIAGRAMA 04 - Família do padre Domingos Vaz

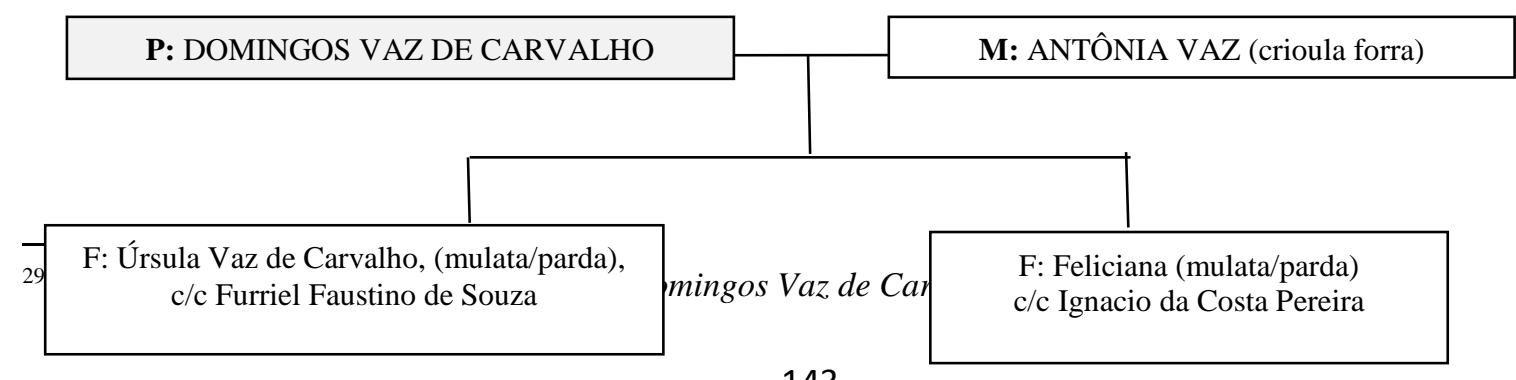




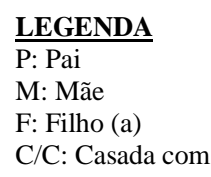

De acordo com as informações constantes acima, o Padre Domingos teve, ao longo de sua vida, ao menos dois relacionamentos mais estáveis: com Maria Lopes, mulher preta, da qual teve quatro filhos - Páscoa, Joaquim Vaz, José Vaz de Carvalho e Rita Vaz de Carvalho; o segundo com Antônia Vaz, crioula, que, de acordo com a declaração do próprio padre, ainda morava em sua companhia e tiveram duas filhas - Úrsula Vaz de Carvalho e Feliciana.

Os relacionamentos vivenciados pelo padre se configuravam como concubinato clerical e, certamente, foi compartilhado, em maior ou menor grau, com a sociedade daquele tempo. Conforme Mattoso (1992), a constituição de famílias por parte dos padres era fato comum e aceito pela sociedade.

Acredita-se que as relações do padre Domingos eram vivenciadas publicamente em Vila Rica. Tal entendimento é reforçado pelo fato de que Antônia Vaz se tornou a inventariante do padre e, portanto, responsável pelos rumos de seus bens. Conforme estabelecido no período, apenas uma pessoa de confiança do falecido e que tivesse conhecimento dos seus bens materiais é que poderia exercer tal função (JULIO, 2017).

Antônia Vaz foi escrava do padre Domingos, o qual the deu a liberdade justificando que o fazia em reconhecimento dos "bons serviços que me tem feito". Além da alforria, dooulhe em testamento alguns trastes de casa, umas casas de sobradinho e uma escrava, ressaltando que Antônia já residia na casa doada e também usufruía dos serviços da mesma cativa. A casa em questão era adjacente a outras pertencentes ao mesmo padre, nas quais moravam, em cada uma delas, o próprio Domingos e o filho, José Vaz. Tais casas eram vizinhas à de sua filha Rita Vaz, conforme esclareceu no testamento: "Declaro que possuo três moradas de casas a saber estas em que moro [...] que partem com o dito meu filho José Vaz, e as segundas místicas as sobreditas que é um sobradinho, e a terceira mística ao dito sobradinho e parte com a de minha filha Rita Vaz [...]"30.

\footnotetext{
${ }^{30}$ AHMINC/IBRAM. Inventário do Padre Domingos Vaz de Carvalho... 1788, fls. 04 e 04v.
} 
A partir de tais declarações é possível vislumbrar uma rede imbricada, na qual o padre pode contribuir para a educação, sustento e orientação dos filhos. Segundo Mendonça (2007), "a presença de uma prole numerosa, o sustento da casa e dos filhos, a divisão de tarefas e a coabitação eram testemunhos evidentes de que conjugalidades em tudo semelhante às das famílias legítimas se abrigavam neste tipo de concubinato clerical”. Como já apontado, o padre Domingos formou uma grande família em Vila Rica, às vistas daquela sociedade, inclusive mantendo as duas filhas tidas com Antônia Vaz em sua companhia e José Vaz e Rita como seus vizinhos ${ }^{31}$. Pode-se perceber nessa convivência uma espécie de "conjunto domiciliar”, na qual o padre conservava seus filhos e a concubina no entorno.

Ainda em relação ao padre, pode-se dizer, a partir das informações presentes no inventário, que o mesmo tinha um conjunto de bens significativo, composto por algumas casas, 11 escravos, vários créditos, algumas joias, roupas, livros e outros bens, que somados foram avaliados em 5:232\$719 1/2.

Os créditos e as joias empenhadas e declaradas entre seus bens revelam uma rede de sociabilidade mantida pelo padre com diferentes pessoas, de condição social variada. Soma-se a isso, o fato de que ele havia assumido a função de escrivão da Irmandade do Santíssimo Sacramento da Freguesia de Conceição de Antônio Dias, Arraial de Vila Rica, o que reforçava sua distinção frente às pessoas daquela localidade.

Mas, para os interesses do presente artigo, interessa as ações desenvolvidas com vistas a casar suas filhas e os negócios que puderam ser estabelecidos a partir das uniões matrimoniais. Consta no testamento que o Padre Domingos havia dotado três de suas cinco filhas - Páscoa, Feliciana e Rita Vaz. A primeira havia recebido um dote no valor de cento e cinquenta mil réis para se casar com o Alferes Francisco Lopes de Oliveira; Feliciana obteve a quantia de quatrocentos mil réis quando se casou com Inácio da Costa Pereira e, finalmente, Rita Vaz de Carvalho foi dotada com um conto de réis para se casar com João Francisco dos Santos.

O dote era uma ferramenta importante no processo matrimonial, pois era uma forma de concorrer para a provisão do futuro da filha e, ao mesmo tempo, contribuir para as atividades econômicas desenvolvidas pelo futuro casal. Conforme destacou Nazzari (2001), a contribuição da esposa com o dote era fulcral para a manutenção da nova família, pois, por

\footnotetext{
31 Conforme declaração feita pelas testemunhas presentes na Sentença Cível de Emancipação movida pela herdeira e filha Mariana Dias de Carvalho, era de "perfeito conhecimento" de todos que o padre era pai dela. Tal fato reforça o fato de que os filhos eram considerados e reconhecidos como do Padre Domingos de maneira "pública" e "notória". AHMINC/IBRAM. Inventário do Padre Domingos Vaz de Carvalho... 1788, n.p.
} 
meio dele, o casal se estabelecia e constituía uma unidade de trabalho. Para além desse aspecto, como já destacado, o dote no período em questão - final do século XVIII e início do século XIX - pode ser percebido como uma materialização da valorização do casamento, tendo em vista que muitas doações feitas em vida ou a partir de legados testamentais estavam condicionados à celebração de matrimônios consagrados para serem efetivamente recebidos.

Das filhas do Padre Domingos que receberam dotes para se casar, cabe algumas considerações sobre Rita Vaz. Ela foi a que recebeu o maior dote, o que provavelmente fez bastante diferença no processo de organização e estabilidade econômica do casal quando este se constituiu. Quando seu pai resolveu fazer o testamento, seu marido João Francisco dos Santos já era falecido, mas, antes disso, ele empreendeu várias atividades econômicas com o sogro. Tal aspecto pode ser visto como um indício de como essa união matrimonial certamente representou um "bom negócio" para a família do Padre Domingos, tendo em vista que, a partir dela, foi possível ampliar e diversificar as atividades econômicas.

João Francisco dos Santos era ferreiro e mineiro ${ }^{32}$. E, assim como declarou em testamento, era sócio de seu sogro numa loja de negócio de caldeireiro e também em uma das minas que possuía. Segundo Alfagali (2012), para que João pudesse exercer o ofício de ferreiro, solicitou sua carta de exame em 1750 à Câmara Municipal de Vila Rica. Além disso, foi juiz de ofício em 1752 e, em 1753, escrivão de ofício no processo de exame do ferrador Domingos Antônio.

É importante destacar também que João Francisco conseguiu estabelecer durante sua vida uma considerável rede de sociabilidade, sendo credor de várias pessoas de diferentes condições, prática também observada no inventário de seu sogro, como mencionado, o que provavelmente contribuiu para se destacarem junto às demais pessoas de Vila Rica. Soma-se a isso, o fato de que, em 1780, João Francisco participou como colaborador da construção do Palácio dos Governadores de Vila Rica (ALFAGALI, 2012).

O fato de João Francisco ter diversificado suas atividades deve ter importante consideração na presente análise. Como foi possível observar a partir das datas mencionadas acima, houve grande participação de João Francisco nas atividades ligadas à arte com ferros no início da década de setenta, período em ele já estava casado com Rita Vaz ${ }^{33}$. Entretanto,

\footnotetext{
${ }^{32}$ AHMINC/IBRAM. Inventário de João Francisco dos Santos... 1788.

${ }^{33}$ Tal afirmação se baseia na declaração feita em seu testamento produzido no ano de 1787 e presente em seu inventário. Segundo a sua declaração, ele era casado a mais de trinta e cinco anos com Rita Vaz, ou seja, pelo menos desde 1752.
} 
não se pode afirmar que essa união matrimonial já existia quando foi examinado para exercer o oficio de ferreiro em 1750. Além disso, não há informação de quando se constituiu a sociedade com o Padre Domingos Vaz. Mas, independentemente de tal aspecto, o consórcio ou a predisposição para exercer diferentes ocupações, dava-lhe importantes qualidades, a ponto de ser considerado um pretendente ideal para famílias que tivessem filhas solteiras e que desejassem orientá-las para um bom e vantajoso casamento.

Diante disso, não se descarta a possibilidade de que o Padre Domingos tenha vislumbrado na pessoa de João Francisco uma oportunidade e, assim, tratou de contratar o casamento de sua filha Rita. João Francisco seria um "genro ideal” e, o casório, uma oportunidade para ampliar a produção e, com isso, aumentar os bens no interior da família.

A parcela de contribuição do Padre Domingos viria a partir do dote significativo que poderia fortalecer os negócios do genro. Uma vez fortalecidos, eles acabariam favorecendo o próprio padre e sua família, pois aumentaria os bens e a influência social e comercial do grupo familiar como um todo. Considerando ainda a sociedade no negócio de caldeiraria e na mineração, o dote seria uma oportunidade de expandir essas atividades. Utilizando-se das palavras de Nazzari (2001, p. 66), "pelo casamento de uma filha, a família ganhava um novo sócio, que podia colaborar para a expansão do empreendimento familiar".

Mas, o casamento entre João Francisco dos Santos e Rita Vaz de Carvalho não trouxe apenas vantagens econômicas para a família do Padre Domingos. Consta no testamento de João que ele era português ${ }^{34}$ o que, no entendimento do período, caracterizava-o como sendo de "qualidade superior". Ora, como já foi mencionado, Rita Vaz era filha da preta Maria Lopes e, sendo assim, carregava uma ascendência escrava. Por isso, o casamento com João Francisco seria uma forma de mobilidade social.

Chama atenção ainda o fato de que esse casamento tenha perdurado por mais de trinta e cinco anos e, além disso, a participação de Rita nos negócios de seu casal. Segundo declaração do próprio João Francisco, a mulher tinha pleno conhecimento de todos os bens que a família possuía. E, além do mais, dos remanescentes de sua terça ${ }^{35}$, nomeava-a como

\footnotetext{
${ }^{34}$ AHMINC/IBRAM. Inventário de João Francisco dos Santos... 1788.

35 Conforme determinado no período, quando uma pessoa falecia e tinha bens e herdeiros menores, era necessário fazer o inventário. Quando casado, a soma de todas as posses deveria ser utilizada para pagamento das dívidas, despesas com o enterro e o restante era então dividido em duas partes: uma para o cônjuge vivo e a outra era pertencente ao falecido. Esta última parte era dividida em outras três: duas para os herdeiros e a terceira poderia ser utilizada conforme a intenção do falecido, tais como para pagamentos de legados, sufrágios, etc. Tal parte era chamada de "terça".
} 
herdeira, porque ela era a "pessoa mais grata com merecimentos da dita herança" 36 . Para completar, ressaltou que, durante o tempo de consórcio que tiveram, Rita havia governado de modo "louvável" e com equilíbrio as diferentes despesas do casal. Tais informações ajudam a vislumbrar o espaço de manobra dessa mulher e certa confluência de papeis, já que são indícios de que Rita participava das atividades econômicas de sua família, merecendo, por isso, ser beneficiada. Esses dados apenas reforçam alguns estudos que já apontaram a participação das mulheres em diferentes aspectos da vida familiar, visando a sobrevivência, manutenção e até mesmo a ascensão de suas famílias ${ }^{37}$.

Do casamento entre João Francisco e Rita Vaz nasceram cinco filhos: Antônio Francisco dos Santos que estava ausente quando foi feito o inventário do pai; Ana Francisca dos Santos casada com José Antônio da Silva Mourão; Maria Francisca dos Santos casada com Joaquim Pereira do Nascimento; Manoel Francisco dos Santos com vinte e sete anos de idade e Feliciano Francisco dos Santos com vinte anos de idade. Pelos dados, apenas Feliciano era menor e, por isso, para cuidar de sua pessoa e administrar suas legítimas, João Francisco nomeou a esposa como tutora.

Ainda sobre os filhos, os dados presentes no inventário de João Francisco revelaram que, de modo semelhante ao sogro, ele dotou as duas filhas para se casarem. Com Ana Francisca despendeu a quantia de setecentos mil réis. Já Maria Francisca recebeu um dote no valor de oitocentos e noventa mil réis.

Além do dote dado à Ana Francisca, João Francisco mencionou que a mesma e o marido viviam em sua companhia. Essa proximidade pode ser inclusive um indício de uma parceria de trabalho estabelecida entre o sogro e seu genro. Tal parceria garantiria a ampliação e fortalecimento das atividades econômicas da família, especialmente se for considerado o fato de que o dote era composto de casa e dois escravos, sendo possível a utilização desses cativos em diferentes ocupações.

Os dados expostos aqui reforçam as considerações apresentadas anteriormente. É possível vislumbrar a sociedade que foi estabelecida primeiramente entre o Padre Domingos e João Francisco e, depois, entre este último e seus genros. Utilizando-se da força de trabalho

\footnotetext{
${ }^{36}$ AHMINC/IBRAM. Inventário de João Francisco dos Santos... 1788, fl. 4v. (Grifos nosso).

${ }^{37}$ Dentre eles, destaca-se: JULIO (2017); CHEQUER (2002); FARIA (1998); FIGUEIREDO (1997), dentre outros.
} 
de cada um e de seus escravos ${ }^{38}$, essa família pôde agir de modo a garantir a sobrevivência de todos e, mais do que isso, construir certa distinção, sobretudo econômica, sendo indício desse aspecto o fato de que alguns de seus membros foram credores para muitos em Vila Rica.

Além disso, a reprodução da prática do dote na família João Francisco é um bom exemplo da apropriação da concepção existente que via o casamento como uma oportunidade de distinção, de dignificar as pessoas e ordenar os envolvidos conforme os preceitos propalados pela Igreja e o Estado.

\section{Considerações finais}

Conforme destacou Brügger (2007), a família interferiu diretamente nos rumos da sociedade. E, uma das formas dessa interferência se deu a partir das relações de poder desenvolvidas no seio familiar. Tais relações se manifestaram em uniões matrimoniais, no reforço do parentesco por meio do apadrinhamento, na ampliação das redes de sociabilidade e na formação de alianças entre os agentes de uma mesma família. Em outros termos, a sociedade não se organizava de forma individual, mas eram os interesses familiares que norteavam seus projetos.

A fim de evidenciar esse poder da família na organização da sociedade, buscou-se, no presente estudo, mostrar as ações para a realização dos casamentos sacramentados. Como foi possível perceber a partir dos dados apresentados, eles representaram um "negócio de família" realmente vantajoso, garantindo o sucesso e a ampliação de negócios e o alcance de determinado status.

O estudo revelou que os padres, de modo semelhante aos demais pais de família, buscou agenciar casamentos na tentativa de construir ou consolidar determinadas relações de poder, sobretudo econômica, através da manutenção ou aumento de suas posses. Para isso, empenharam-se em estabelecer contratos matrimoniais dentro e fora de seus grupos familiares.

Ao mesmo tempo, a partir dos dados analisados, foi possível perceber que os casamentos "a face da Igreja e do Estado" foram buscados enquanto um valor mesmo para aquelas famílias constituídas fora do sacramento, pois representava uma "qualidade" aos olhos dos outros. Nesse sentido, seguindo o entendimento do período, as famílias exerceram

\footnotetext{
${ }^{38}$ Conforme é possível identificar no inventário, dois dos oito escravos de João Francisco eram oficiais de ferreiros. Além deles, outros quatro eram mineiros. Certamente esses cativos auxiliavam seu senhor na atividade de mineração e no serviço com ferro. AHMINC/IBRAM. Inventário de João Francisco dos Santos... 1788 , fl 12.
} 
sua função educativa e criaram estratégias para ordenar seus membros, dentre elas, a obediência à política civil e religiosa que pregava a necessidade do matrimônio celebrado pela Igreja.

É certo que o casamento servia, muitas vezes, apenas para atestar alianças já existentes e que relações amorosas existiram para além do sacramento, isso porque, não se pode esquecer que ele foi uma instituição primordialmente da elite. Na verdade, como apontou Figueiredo (1997), em Minas Gerais, houve uma multiplicação de uniões consensuais à margem dos ensinamentos da Igreja e do Estado. Entretanto, importante reforçar, os dados demonstraram que houve uma preocupação, inclusive por parte daquelas pessoas que viviam essas relações consensuais, de fazer que seus filhos casassem legalmente.

Diante desses aspectos, pode-se conjecturar que a busca pelo casamento sacramentado teve diferentes intenções. Mas, independentemente dos interesses que moveram a celebração de um matrimônio, o certo é que ele se revelou como uma estratégia importante para a constituição e organização da sociedade mineira no período focalizado.

\section{FONTES MANUSCRITAS}

ACSM/IPHAN. Inventário do Padre Francisco José da Fonseca. 1748. Localizado em: ACSM/IPHAN, Mariana - MG ( $1^{\circ}$ Ofício, Caixa 22, Auto 589)

AEMNSP/SJDR. Registro de Casamento de Ana Custódia. 1811. Localizado em: AEMNSP, São João del-Rei - MG. (Livro 2, fl. 641).

AHETII/IPHAN/SJDR. Escritura de Perfilhação do Padre João da Costa Guimarães. 1819. Localizado em: AHETII/IPHAN, São João del-Rei. (Livro de Notas 03/ 2º ofício. 1818-1821, fl. $47 \mathrm{v})$.

AHETII/IPHAN/SJDR. Inventário do Padre André Vaz de Siqueira. 1827. Localizado em: AHETII/IPHAN, São João del-Rei - MG. (Caixa c-30).

AHETII/IPHAN/SJDR. Inventário do Padre Francisco Ferreira da Silva. 1843. Localizado em: AHETII/IPHAN, São João del-Rei - MG (Caixa 452).

AHETII/IPHAN/SJDR. Inventário do Padre Felisberto Rodrigues Milagres. 1854. Localizado em: AHETII/IPHAN, São João del-Rei. (Caixa 394).

AHETII/IPHAN/SJDR. Inventário do Padre João da Costa Guimarães. 1836. Localizado em: AHETII/IPHAN, São João del-Rei. (Caixa 480).

AHETII/IPHAN/SJDR. Inventário do Padre José Maria Correa Pamplona. 1854. Localizado em: AHETII/IPHAN, São João del-Rei - MG (Caixa 564). 
AHETII/IPHAN/SJDR. Inventário de Lourenço José Fernandes Brasiel. 1833. Localizado em: AHETII/IPHAN, São João del-Rei - MG. (Caixa 128).

AHETII/IPHAN/SJDR. Inventário de Senhorinha Cândida Rodrigues. 1855. Localizado em: AHETII/IPHAN, São João del-Rei, MG (caixa 220).

AHMINC/IBRAM. Inventário do Padre Domingos Vaz de Carvalho. 1788. Localizado em: AHMINC/IBRAM, Ouro Preto - MG. ( $1^{\circ}$ Ofício, Códice 41, Auto 485)

AHMINC/IBRAM. Inventário de João Francisco dos Santos. 1788. Localizado em: AHMINC/IBRAM, Ouro Preto - MG. (1º Ofício, Códice 70, Auto 831).

AHMPAS/BARBACENA. Testamento do padre José Joaquim de Carvalho. 1844. Localizado em: AHMPAS, BARBACENA - MG. (Livro: 1840-1846. Caixa 287, 1SVC, fl. 72)

\section{REFERÊNCIAS}

ALFAGALI, C. G. M. Em casa de ferreiro pior apeiro: os artesãos do ferro em Vila Rica e Mariana no século XVIII. Dissertação (Mestrado em História) Universidade Estadual de Campinas, Campinas, 2012.

ALGRANTI, L. M. Famílias e vida doméstica. In: SOUZA, L. de M. (Org.). História da vida privada no Brasil: cotidiano e vida privada na América Portuguesa, vol. 1. São Paulo: Companhia das Letras, 1997;

ANDRADE, M. F. de. Elites regionais e a formação do Estado imperial brasileiro: Minas Gerais - Campanha da Princesa (1799-1850). Rio de Janeiro: Arquivo Nacional, 2008.

ANTUNES, A. de A. Fiat Justitia: os advogados e prática da justiça em Minas Gerais (1750 - 1808). Tese (Doutorado em História). Universidade Estadual de Campinas, Campinas, 2005.

BRUGGER, S. M. J. Minas patriarcal: família e sociedade (São João del-Rei - séculos XVIII e XIX). São Paulo: Annablume, 2007.

CAMPOS, A. L. de A. Casamento e família em São Paulo colonial: caminhos e descaminhos. São Paulo: Paz e Terra, 2003.

CERCEAU NETTO, Rel. Um em casa de outro: concubinato, família e mestiçagem na Comarca do Rio das Velhas (1720-1780). São Paulo: Annablume; Belo Horizonte: PPGH/UFMG, 2008, p. 45.

CHEQUER, R. M. P. Negócios de família, gerência de viúvas: senhoras administradoras de bens e pessoas (Minas Gerais 1750-1800). Dissertação (Mestrado em História). Universidade Federal de Minas Gerais, Belo Horizonte: 2002 
COELHO, E. L. Coalhadas e rapaduras: estratégias de inserção social e sociabilidades de músicos negros - São João del-Rei, século XIX. Dissertação (Mestrado em História) Universidade Federal de São João del-Rei, São João del-Rei, 2011.

CORRÊA, M. Repensando a família patriarcal brasileira. In: ALMEIDA, M. S. K.; ARANTES, A. A. et al. Colcha de Retalhos: estudos sobre a família no Brasil. São Paulo: Brasiliense, 1982.

COTTA, F. A. Breve História da Polícia Militar de Minas Gerais. Belo Horizonte: Fino Traço, 2014.

FARIA, S. C. A Colônia em Movimento: fortuna e família no cotidiano colonial. Rio de Janeiro: Nova Fronteira, 1998.

FARIA, S. C. História da família e demografia histórica. In: CARDOSO, C. F.; VAINFAS, R. (Org.). Domínios da história: ensaios de teoria e metodologia. 2. Ed. Rio de Janeiro: Elsevier, 2011.

FIGUEIREDO, L. R. de A. Barrocas famílias: vida familiar em Minas Gerais no século XVIII. São Paulo: HUCITEC, 1997.

FONSECA, T. N. de L. e. Instituições e práticas educativas na América Portuguesa no século XVIII e primeiras décadas. Projeto de Pesquisa Universal CNPq. Belo Horizonte: Universidade Federal de Minas Gerais, 2014b.

FREYRE, G. Casa-grande \& senzala: formação da família brasileira sob o regime da economia patriarcal. 51. ed. São Paulo: Global, 2006.

JULIO, K. L. "Os têm tratado e educado" - as mulheres e suas ações para a manutenção da família e a educação de menores no termo de Vila Rica, MG (1770 - 1822). Tese (Doutorado em Educação) Universidade Federal de Minas Gerais. Belo Horizonte: 2017.

LEWCOWICZ, I. As mulheres mineiras e o casamento: estratégias individuais e familiares nos séculos XVIII e XIX. Departamento de estudos históricos básicos. UNESP: São Paulo, 1993.

LOTT, M. M. Na forma do ritual romano: casamento e família em Vila Rica (1804-1839). São Paulo: Annablume; Belo Horizonte: PPGH/UFMG, 2008.

MATTOSO, K. M. de Q. Bahia, século XIX: uma província no Império. Rio de Janeiro: Nova Fronteira, 1992.

MENDONÇA, P. G. Sacrílegas famílias: conjugalidades clericais no Bispado do Maranhão no século XVIII. Dissertação (Mestrado em História) Universidade Federal Fluminense. Niterói, RJ, 2007.

NAZZARI, M. O desaparecimento do dote: mulheres, famílias e mudança social em São Paulo, Brasil, 1600-1900. Trad. Lólio Lourenço de Oliveira. São Paulo: Companhia das Letras, 2001. 
NOLASCO, E. A. Por fragilidade Humana - constituição familiar do clero: em nome dos padres e filhos - São João del-Rei, (século XIX). Dissertação (Mestrado em História). Universidade Federal de São João del-Rei, São João del-Rei, 2014;

PRAXEDES, V. L. Segurando as pontas e tecendo tramas: mulheres chefes de domicílio em Minas Gerais 1770 - 1880. Tese (Doutorado em História). Universidade Federal de Minas Gerais, Belo Horizonte, 2008.

SAMARA, E. de M. As mulheres, o poder e a família: São Paulo, século XIX. São Paulo: Marco Zero, 1989.

SILVA, K. V.; SILVA, M. H. Dicionário de conceitos históricos. 3. ed. São Paulo: Contexto, 2010. 